\title{
Broadband Gap-coupled Variations of Equilateral Triangular Microstrip Antennas
}

\author{
Amit A. Deshmukh \\ EXTC, DJSCOE \\ Vile - Parle (W), \\ Mumbai, India
}

\author{
Shafin Nagarbowdi \\ EXTC, DJSCOE \\ Vile - Parle (W), \\ Mumbai, India
}

\author{
Neelam Phatak \\ EXTC, DJSCOE \\ Vile - Parle (W), \\ Mumbai, India
}

\begin{abstract}
Various broadband multi-resonator gap-coupled configurations of equilateral triangular microstrip antenna and its compact variation, half equilateral triangular microstrip antenna, are proposed. The broadband proximity fed equilateral triangular microstrip antenna yields bandwidth of more than $650 \mathrm{MHz}(\sim 4 \%)$, whereas equivalent proximity fed gap-coupled half equilateral triangular microstrip antennas yields bandwidth of more $700 \mathrm{MHz}(\sim 47 \%)$. The bandwidth of proximity fed equilateral triangular and half equilateral triangular microstrip antennas is further increased by using gap-coupled configurations with equal and unequal dimensions compact half equilateral microstrip antennas. These gap-coupled configurations yields bandwidth of more than $800 \mathrm{MHz}(>50 \%)$ with broadside radiation pattern and peak gain of nearly $8 \mathrm{dBi}$.
\end{abstract}

\section{Keywords}

Equilateral triangular microstrip antenna, Half equilateral triangular microstrip antenna, Broadband microstrip antenna, Compact microstrip antenna, Proximity feeding

\section{INTRODUCTION}

The simplest method to realize broadband microstrip antenna (MSA) is fabricating the patch on air substrate of thickness more than $0.1 \lambda_{0}$, in conjunction with the proximity feeding technique $[1-5]$. The use of lower dielectric constant substrate reduces the quality factor of the cavity below the patch that realizes increased bandwidth $(\mathrm{BW})$, whereas proximity feeding technique realizes impedance matching using thicker substrates. The broadband MSA is also realized by using multi-resonator gap-coupled and stacked configurations $\left[\begin{array}{llll}1, & 6 & - & 9\end{array}\right]$. Although multi-resonator configuration increases antenna size but it increases antenna gain and BW. Without increasing the patch size, broadband MSA is realized by cutting the slot at an appropriate position inside the patch $[10-16]$. The slot cut MSA is relatively complex in design as compared to multi-resonator configurations. At the dominant mode of operation, compact MSA is realized either by placing the shorting post along the zero field line of the patch or by cutting the slot inside the patch or by using the symmetry of the patch with respect to the feed point axis and using only half of the configuration [1]. The compact variations of equilateral triangular MSA (ETMSA) are realized by placing the shorting posts along the zero field line at its fundamental $\mathrm{TM}_{10}$ mode or by using symmetry of ETMSA across feed point axis thereby realizing compact half ETMSA (HETMSA) [1]. To increase the BW of ETMSA and compact ETMSAs, their gap-coupled configurations with parasitic patches are reported [1]. The gap-coupled configurations of ETMSAs increase total antenna size whereas gap-coupled compact variations of ETMSAs have lower gain.

In this paper, various gap-coupled configurations of ETMSAs and compact HETMSAs are proposed. In the gap-coupled configurations compact HETMSAs of equal and unequal dimensions were gap-coupled to ETMSA and HETMSA along their side lengths, thereby maintaining the same overall antenna size. First the proximity fed ETMSA is proposed. It gives $\mathrm{BW}$ of more than $650 \mathrm{MHz}(\sim 44 \%)$ with broadside radiation pattern and peak gain of nearly $7 \mathrm{dBi}$. Further proximity fed ETMSA is divided into two equal dimension HETMSAs, and their gap-coupled configuration yields BW of more than $700 \mathrm{MHz}(\sim 47 \%)$ with similar gain and radiation pattern characteristics. Further increase in the BW of gapcoupled HETMSAs is obtained by using two unequal dimensions of HETMSAs, which realizes BW of more than $800 \mathrm{MHz}(>50 \%)$. The proximity fed ETMSA gap-coupled with either equal or unequal dimensions HETMSAs, are proposed. With equal dimension HETMSAs it yields BW of $780 \mathrm{MHz}(\sim 51 \%)$ whereas unequal dimension patches yields BW of $845 \mathrm{MHz}(\sim 54 \%)$. Both these configurations shows broadside radiation pattern with peak gain of $8.0 \mathrm{dBi}$. Similarly gap-coupled configurations of proximity fed HETMSAs with equal and unequal dimension HETMSAs are proposed. These configurations yields BW of more than 800 $\mathrm{MHz}(>50 \%)$ with broadside radiation pattern and a peak gain of $8 \mathrm{dBi}$. The above gap-coupled configurations were proposed in $1500 \mathrm{MHz}$ frequency band. To realize broader BW they were optimized on air substrate of thickness $3.0 \mathrm{~cm}$ $\left(0.15 \lambda_{0}\right)$. The proximity feeding technique is used to feed the MSAs, since it is a simpler method to be implemented in thicker substrates. The ETMSAs and HETMSAs were first optimized using IE3D software using infinite as well as finite ground planes [17]. For measurements, the MSAs were fabricated using copper strip having finite thickness and were supported in air using foam spacer supports. The foam spacers were also used to maintain the required air gap between fed and parasitic patches. The MSA were fed using N-type connector of $0.32 \mathrm{~cm}$ inner wire diameter and measurements were carried out using $\mathrm{R} \& \mathrm{~S}$ vector network analyzer using finite square ground plane of side length $80 \mathrm{~cm}$. In all the configurations, a good agreement is obtained between the simulated and measured results.

\section{PROXIMITY FED ETMSA AND HETMSAs}

The proximity fed ETMSA is shown in Fig. 1(a, b). For the given substrate thickness, the side length ' $\mathrm{S}$ ' is calculated such that it operates in its $\mathrm{TM}_{10}$ mode at frequency of around $1500 \mathrm{MHz}$ [1]. The 'S' was found to be $10 \mathrm{~cm}$. The coupling rectangular strip is placed below the patch at substrate 
thickness of $2.8 \mathrm{~cm}\left(0.14 \lambda_{0}\right)$. The ETMSA is simulated using IE3D software and its resonance curve plot is shown in Fig. 1(d). The plot shows peak due to fundamental $\mathrm{TM}_{10}$ and higher order $\mathrm{TM}_{11}$ modes. At $\mathrm{TM}_{10}$ mode, by optimizing the strip dimensions and its position below the patch, a broadband response as shown in Fig. 1(e) is obtained.

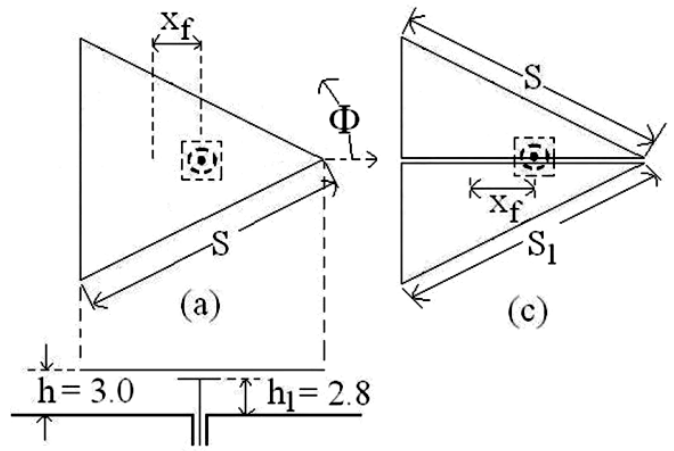

(b)
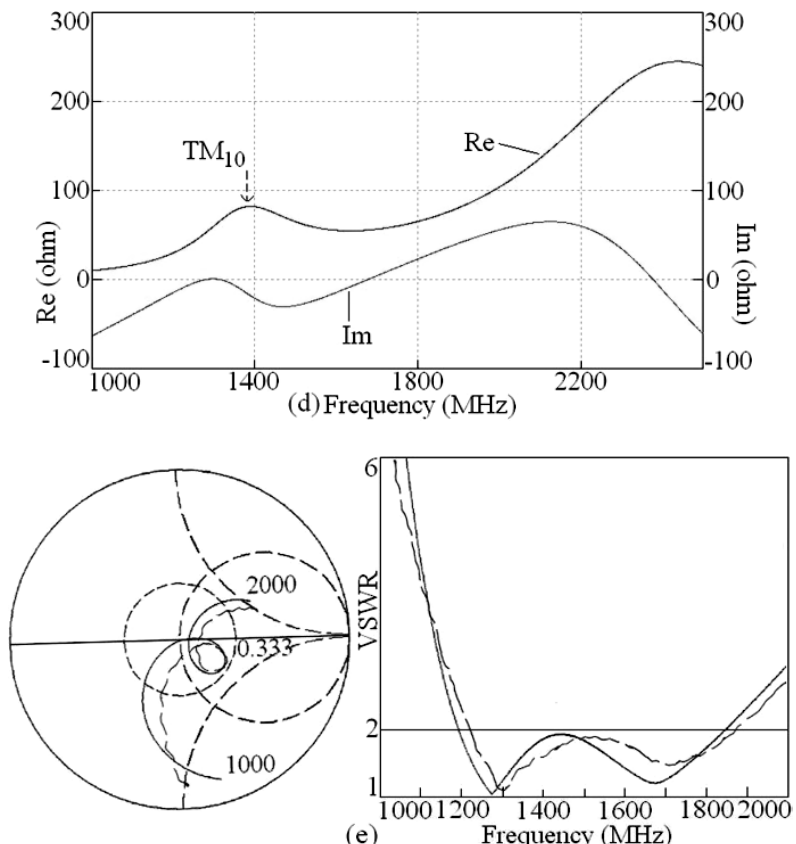

Fig. 1 Proximity fed (a, b) ETMSA, (c) HETMSA, (d) resonance curve plot for proximity fed ETMSA and its (e) input impedance and VSWR plots, $(-)$ simulated, (--) measured

The simulated BW is $674 \mathrm{MHz}(44 \%)$ whereas the measured BW is $682 \mathrm{MHz}(44.2 \%)$. The antenna shows broadside radiation pattern over the complete $\mathrm{BW}$ with peak gain of nearly $7.1 \mathrm{dBi}$ as shown in Fig. 2(a). Further using the symmetry of $\mathrm{TM}_{10}$ mode field distribution of ETMSA across the feed point axis, a HETMSA has been realized and gapcoupled configuration of equal dimension $\left(\mathrm{S}=\mathrm{S}_{1}\right)$ proximity fed HETMSAs is shown in Fig. 1(c). By optimizing the air gap between two patches a broader BW is realized as shown in Fig. 2(b). For air gap of $0.4 \mathrm{~cm}$ between the two patches, the simulated BW is $729 \mathrm{MHz}(47.2 \%)$ whereas the measured BW is $738 \mathrm{MHz}(47.6 \%)$. The gap-coupled HETMSA shows nearly the same gain and radiation pattern characteristics as that given by proximity fed ETMSA as shown in Fig. 2(a). The fabricated prototype of the two configurations is shown in Fig. 2(c, d).

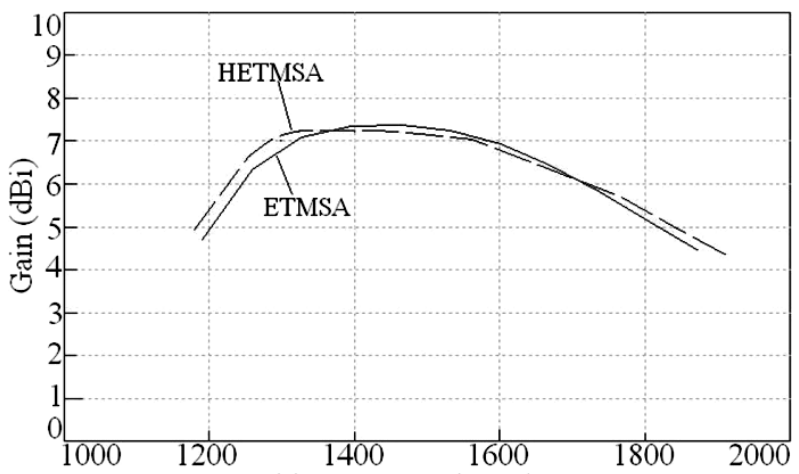

(a) Frequency $(\mathrm{MHz})$

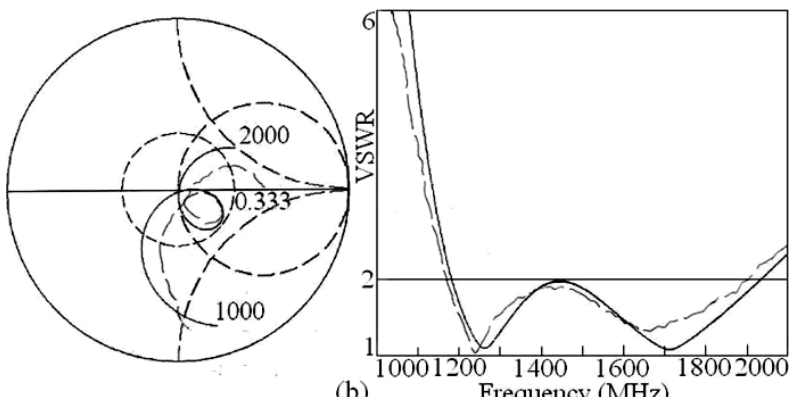

(b)

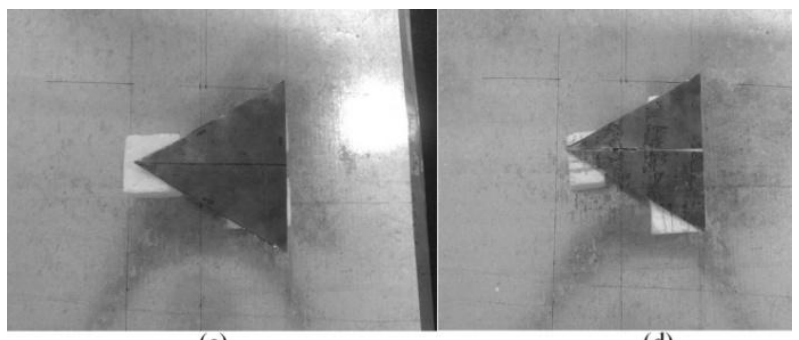

(c)

Fig. 2 (a) Gain variation over BW for ETMSA and HETMSA, (b) input impedance and VSWR plots, (-) simulated, (--) measured, for proximity fed gap-coupled HETMSAs and fabricated prototype for (c) ETMSA and (d) gap-coupled HETMSAs

Further increase in the BW for gap-coupled configuration is realized for different values of $S_{1}$. With decrease in $S_{1}$, the $\mathrm{TM}_{10}$ mode resonance frequency of relevant HETMSA reduces. For larger difference between two resonance frequencies, the shift in the radiation pattern away from the broadside direction is noticed. Thus optimum BW is realized when the shift in the radiation pattern away from broadside direction is not more than $3 \mathrm{dBi}$ [1]. This is obtained for $\mathrm{S}_{1}=$ $8.6 \mathrm{~cm}$ and its input impedance and VSWR plots are shown in Fig. 3(a). The simulated BW is $823 \mathrm{MHz}(50.8 \%)$, whereas the measured $\mathrm{BW}$ is $836 \mathrm{MHz}(51.1 \%)$. The fabricated prototype of the configuration is shown in Fig. 3(b). The radiation pattern at two frequencies over BW and gain variation over the same are shown in Fig. 3(c, d) and 4, respectively. The pattern is in the broadside direction with peak gain of nearly $7.6 \mathrm{dBi}$. The $\mathrm{E}$ and $\mathrm{H}$-planes are aligned along $\Phi=0^{\circ}$ and $90^{\circ}$, respectively. Since the larger ground plane is used, back lobe radiation is smaller, and hence it is not shown in the radiation pattern plot. To further improve upon the BW and gain of above proximity fed ETMSAs, their gap-coupled configurations with compact HETMSAs are proposed as discussed in the following section. 

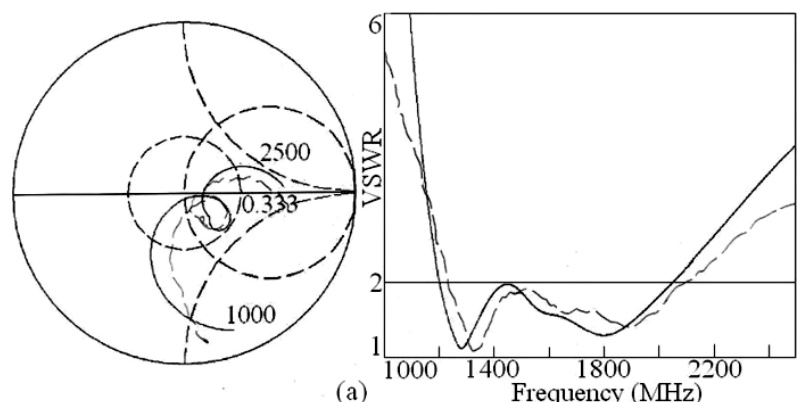

(a)

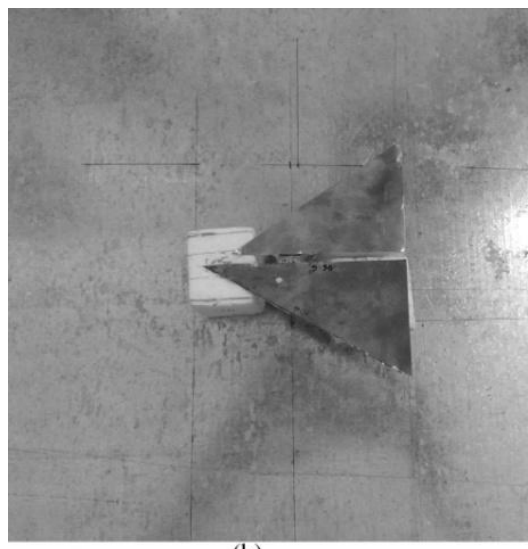

(b)

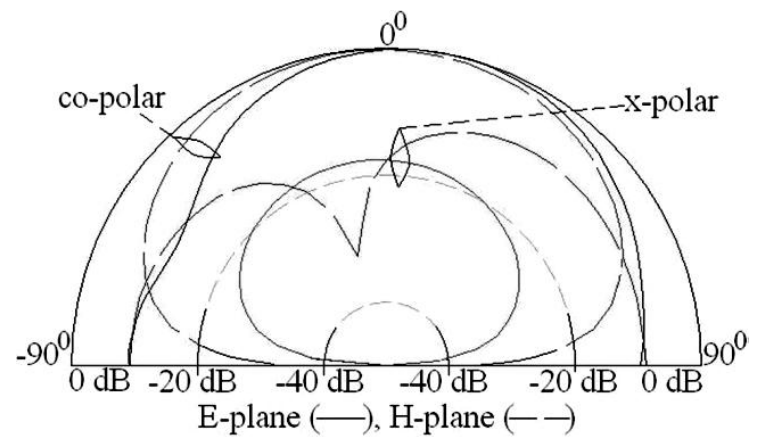

(c) $\mathrm{f}=1418 \mathrm{MHz}$

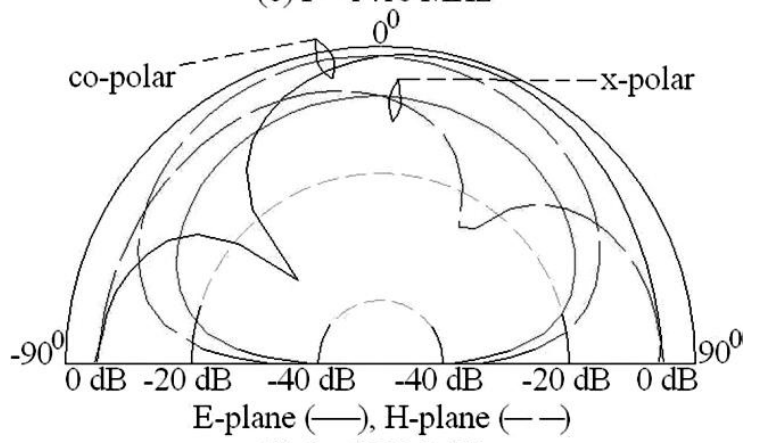

(d) $\mathrm{f}=1820 \mathrm{MHz}$

Fig. 3 (a) Input impedance and VSWR plots, $(-)$ simulated, (--) measured, (b) fabricated prototype and (c, d) radiation pattern over BW for proximity fed gapcoupled unequal dimension HETMSAs

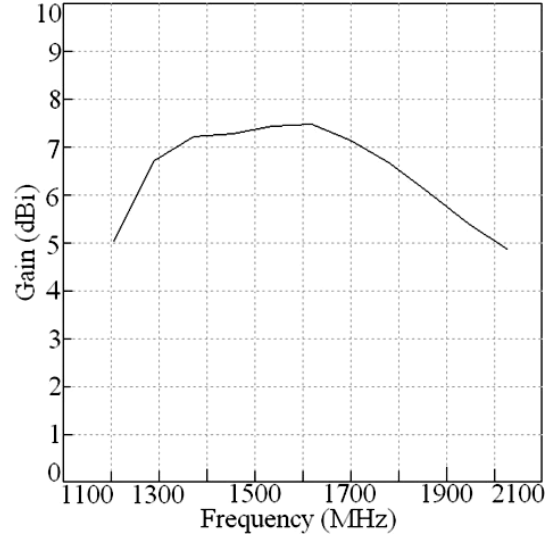

Fig. 4 Gain variation over BW for proximity fed gapcoupled unequal dimension HETMSAs

\section{PROXIMITY FED GAP-COUPLED ETMSAs AND HETMSAs}

The gap-coupled configuration of ETMSA with two equal dimension HETMSAs is shown in Fig. 5(a). Two compact HETMSAs having side length ' $\mathrm{S}_{1}$ ', smaller than that of fed ETMSA, are gap-coupled. By optimizing the air gap between two patches, a broader BW as shown in Fig. 5(b) is obtained.

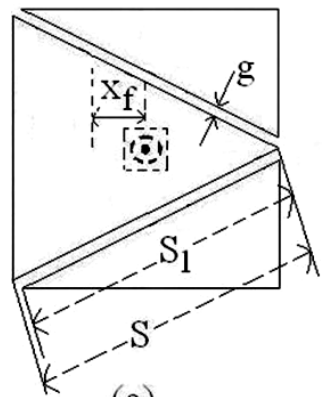

(a)

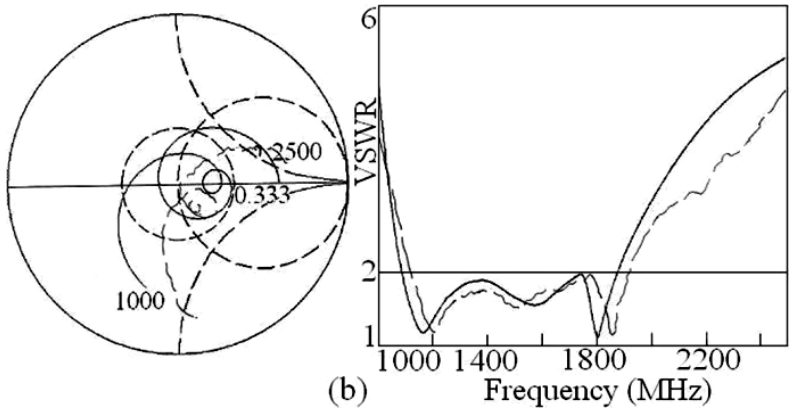

Fig. 5 (a) Proximity fed ETMSA gap-coupled to HETMSAs and its (b) input impedance and VSWR plots, $(-)$ simulated, $(--)$ measured

The optimized response is obtained for $\mathrm{h}=3.0 \mathrm{~cm}, \mathrm{~h}_{1}=2.8$ $\mathrm{cm}, \mathrm{S}=10 \mathrm{~cm}$ and $\mathrm{S}_{1}=8.6 \mathrm{~cm}$. The simulated $\mathrm{BW}$ is 780 $\mathrm{MHz}(52.5 \%)$ whereas the measured $\mathrm{BW}$ is $794 \mathrm{MHz}$ $(53.2 \%)$. The radiation pattern at center frequency and gain variation over BW are shown in Fig. 6(a,b). The radiation pattern at center frequency and over the $\mathrm{BW}$ is in the broadside direction. The antenna gain is more than $7 \mathrm{dBi}$ over most of the BW with peak gain of nearly $8.0 \mathrm{dBi}$. The fabricated prototype of the above configuration is shown in Fig. 6(c). Further the above gap-coupled configuration is optimized for different values of $S_{1}$, i.e. parasitic HETMSA 
dimensions. The optimized response for parasitic HETMSAs of side length 8.6 and $7.2 \mathrm{~cm}$, respectively is shown in Fig. $6(d)$.

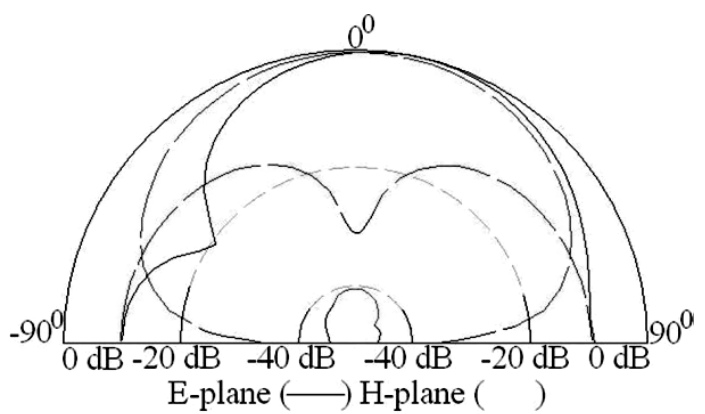

(a) $\mathrm{f}=1410 \mathrm{MHz}$

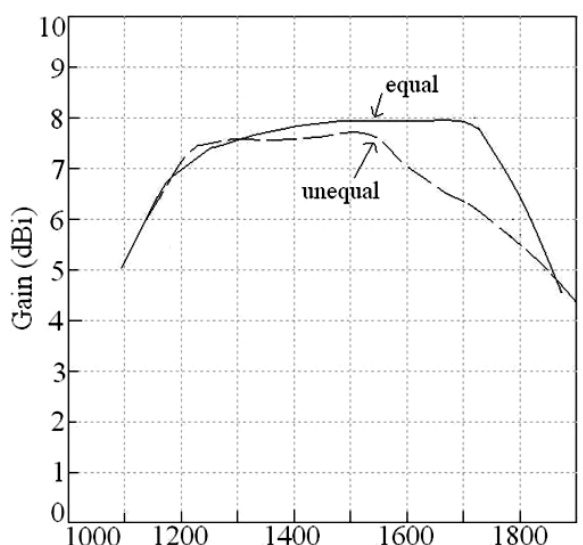

(b) Frequency $(\mathrm{MHz})$

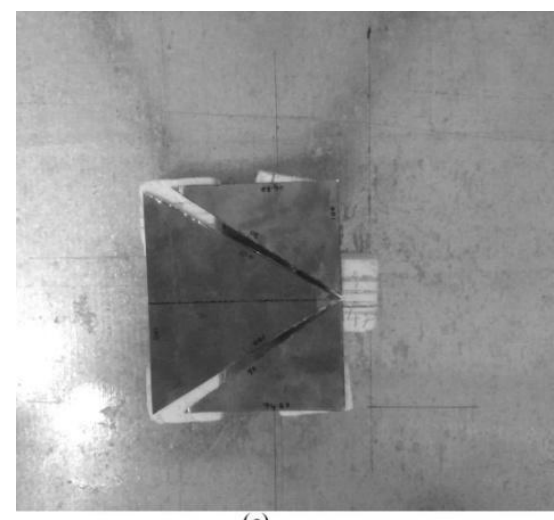

(c)

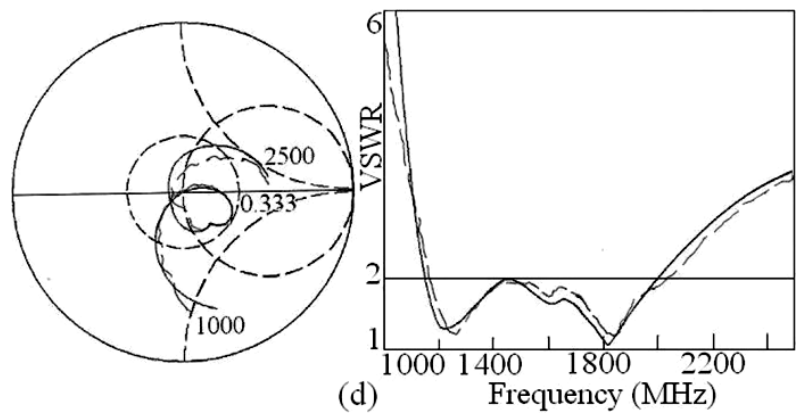

Fig. 6 (a) Radiation pattern at center frequency, (b) gain variation over BW and (c) fabricated prototype of proximity fed ETMSA gap-coupled to HETMSAs, (d) input impedance and VSWR plots for proximity fed ETMSA gap-coupled to unequal dimension HETMSAs, $(-)$ simulated, $(--)$ measured
The simulated $\mathrm{BW}$ is $845 \mathrm{MHz}(53.6 \%)$ whereas the measured BW is $862 \mathrm{MHz}(54 \%)$. The radiation pattern for this configuration is in the broadside direction with higher cross polar levels towards higher frequencies of $\mathrm{BW}$. The higher cross polar levels reduces antenna gain at those frequencies as shown in Fig. 6(b). The fabricated prototype of this configuration is shown in Fig. 7(a). Further gap-coupled configurations of gap-coupled HETMSAs are proposed. An equal dimension gap-coupled HETMSAs configuration is shown in Fig. 7(b). In this configuration, dimensions of proximity fed HETMSAs (i.e. in the center) are equal and that of the parasitic HETMSAs are equal and they are different than the dimensions of proximity fed HETMSAs. By optimizing the dimensions of patches and air gap between them, a broadband response as shown in Fig. 7(c) is obtained. The simulated $\mathrm{BW}$ is $785 \mathrm{MHz}(51.6 \%)$ whereas the measured BW is $804 \mathrm{MHz}(52.5 \%)$. The fabricated prototype of the configuration, radiation pattern at center frequency and gain variation over BW are shown in Fig. 8(a-c).

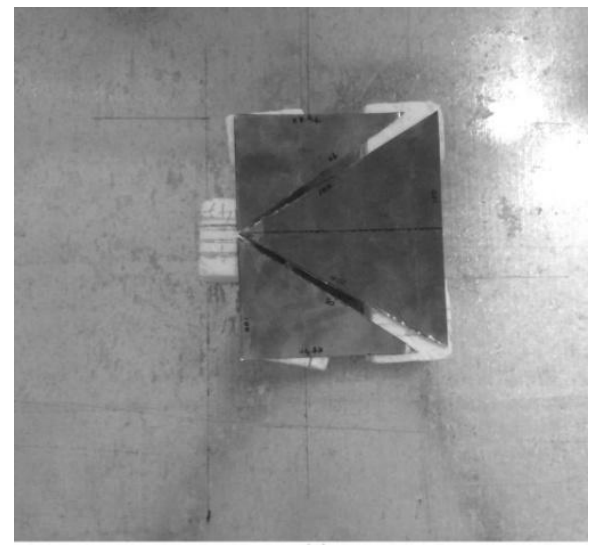

(a)
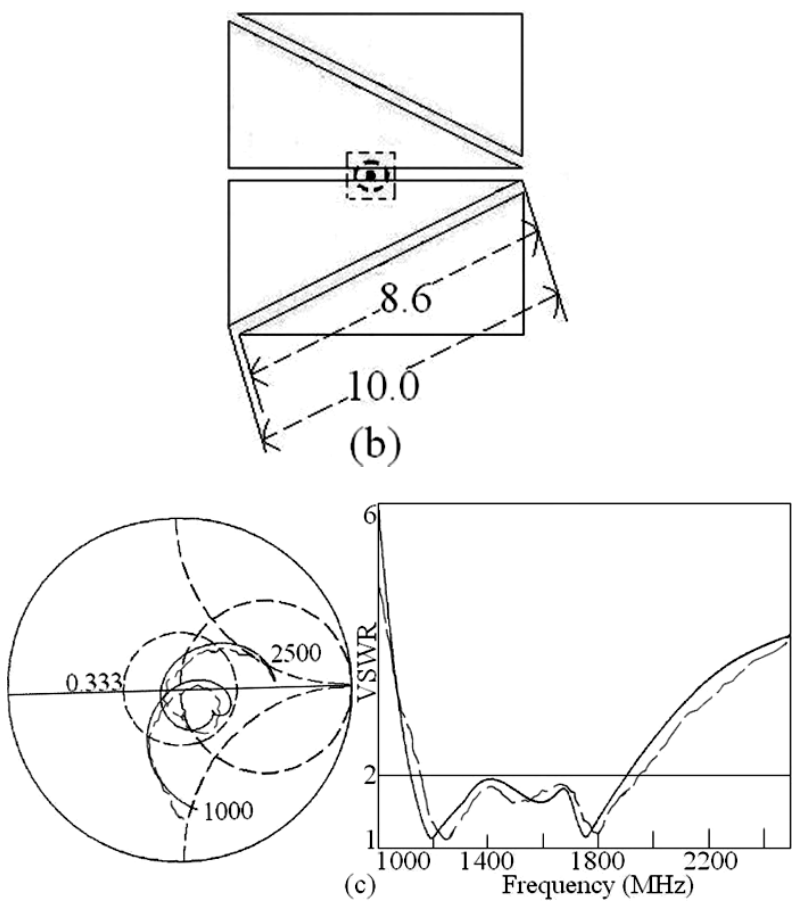

Fig. 7 (a) Fabricated prototype of proximity fed ETMSA gap-coupled to unequal dimension HETMSAs, (b) proximity fed gap-coupled HETMSAs and its (c) input impedance and VSWR plots, $(-)$ simulated, $(--)$ measured 


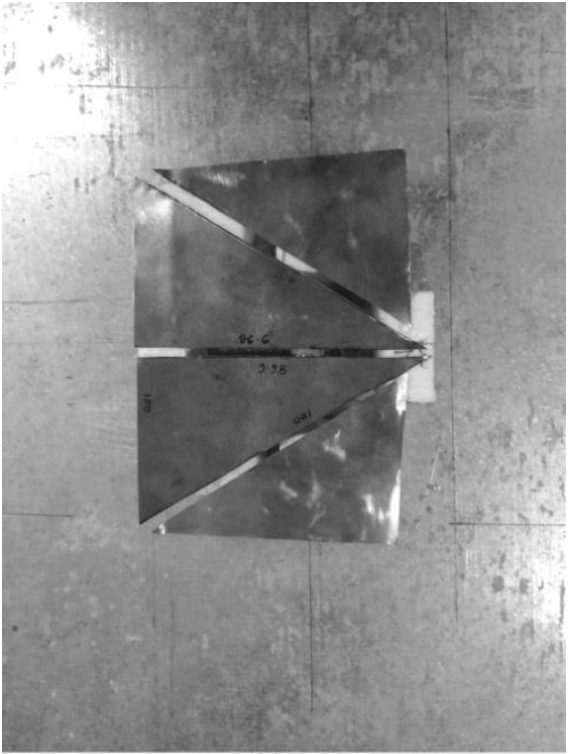

(a)

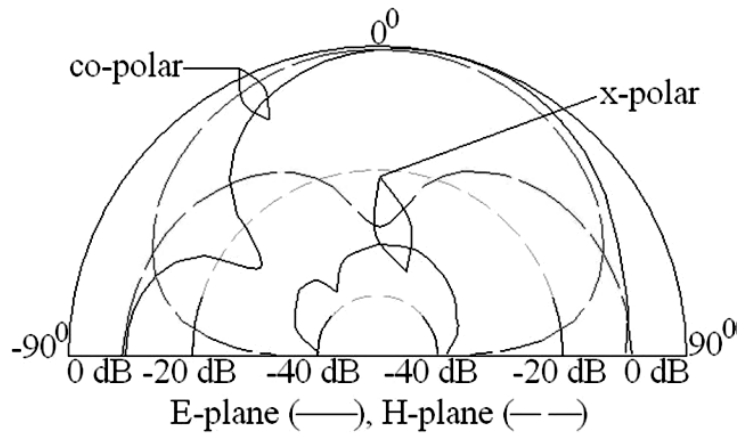

(b) $\mathrm{f}=1520 \mathrm{MHz}$

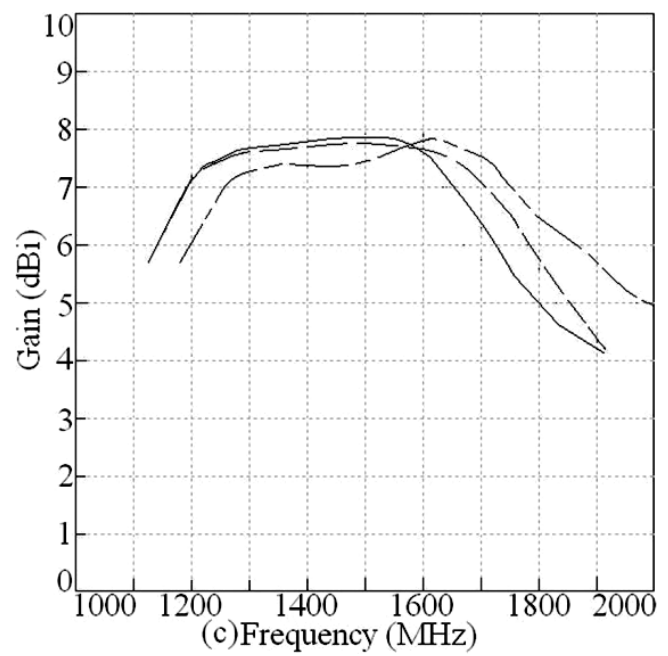

Fig. 8 (a) Fabricated prototype, (b) radiation pattern at center frequency for of proximity fed equal dimension

HETMSAs and (c) gain variation over BW for configuration shown in $(-)$ Fig. 7(b), (--) Fig. 9(a), (--) Fig. 10(b)

The radiation pattern at center frequency and over the BW is in the broadside direction with a peak gain of nearly $8 \mathrm{dBi}$. To further increase the BW, parasitic HETMSAs with unequal dimensions are gap-coupled, as shown in Fig. 9(a). Using unequal HETMSA dimensions, different resonance frequencies are realized and realized BW depends upon the inter-spacing between various resonance frequencies. In this case the simulated $\mathrm{BW}$ is $788 \mathrm{MHz}(51.8 \%)$ whereas the measured BW is $802 \mathrm{MHz}$ (52.3\%) as shown in Fig. 9(b). The fabricated prototype of the configuration and radiation pattern at center frequency is shown in Fig. 9(c) and 10(a), respectively. The gain variation over BW is shown in Fig. 8(c). This configuration shows similar gain and radiation pattern characteristics as shown by proximity fed gap-coupled HETMSAs with equal patch dimensions. The gap-coupled configuration with unequal proximity fed HETMSAs dimension gap-coupled to equal dimension HETMSAs is also studied as shown in Fig. 10(b).
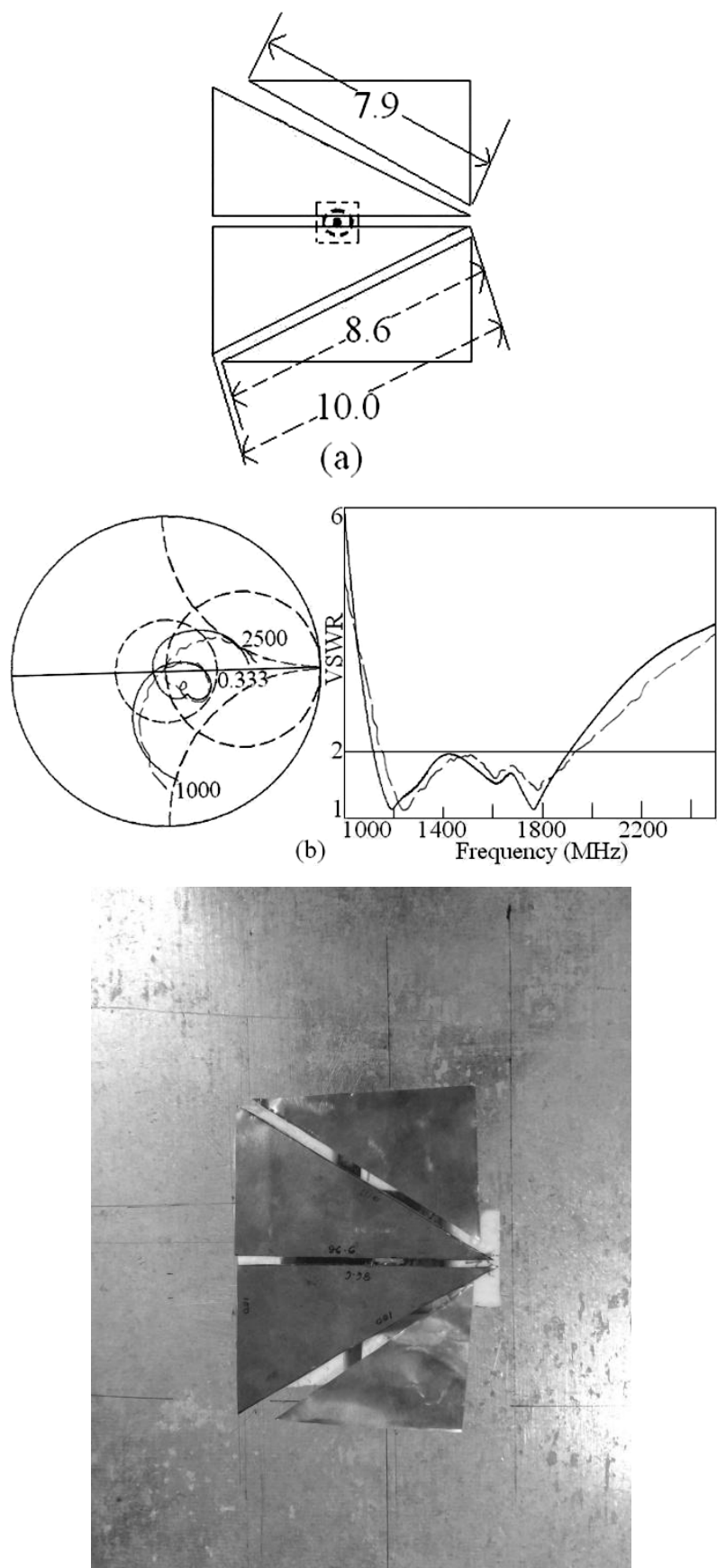

(c)

Fig. 9 (a) Proximity fed HETMSAs gap-coupled to unequal dimension HETMSAs, its (b) input impedance and VSWR plots, $(-)$ simulated, $(--)$ measured and its (c) fabricated prototype 
The optimized input impedance and VSWR plots, fabricated prototype, radiation pattern at center frequency and gain variation over BW are shown in Fig. 11(a-c) and 8(c), respectively. The simulated $\mathrm{BW}$ is $810 \mathrm{MHz}(52.4 \%)$ whereas the measured $\mathrm{BW}$ is $824 \mathrm{MHz}(53.2 \%)$. The radiation pattern over the BW is in broadside direction with peak gain of nearly $8 \mathrm{dBi}$. Due to unequal proximity fed HETMSA dimensions, this configuration shows reduced gain towards lower frequencies of BW. The results for all the configurations are summarized in Table 1. In terms of BW, radiation pattern and gain, gap-coupled configuration of proximity fed ETMSA with equal as well as unequal dimension HETMSAs gives optimum results.

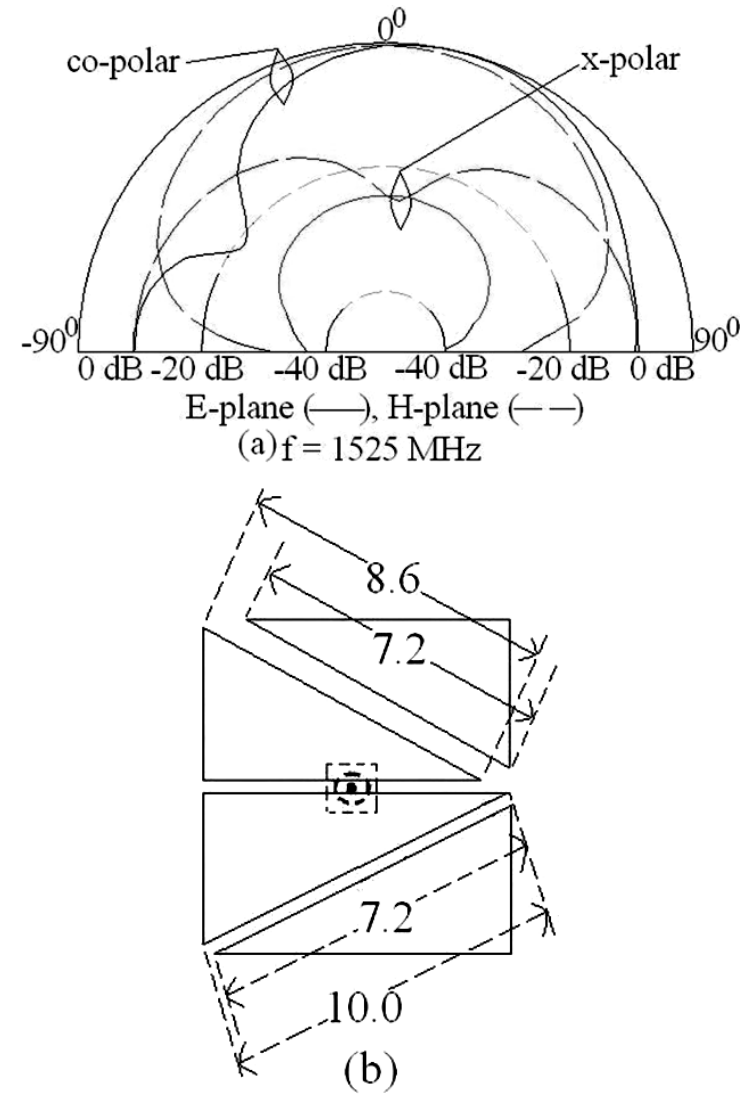

Fig. 10 (a) Radiation pattern at center frequency for proximity fed unequal dimension HETMSAs, and (b) proximity fed unequal dimension HETMSAs gap-coupled to equal dimension HETMSAs

Table 1 Comparison between various proximity fed gapcoupled ETMSAs and HETMSAs

\begin{tabular}{|c|c|c|c|}
\hline $\begin{array}{c}\text { Configuration } \\
\text { shown in }\end{array}$ & $\begin{array}{c}\text { Simulated } \\
\text { BW, } \\
(\mathrm{MHz}, \%)\end{array}$ & $\begin{array}{c}\text { Simulated } \\
\text { BW, } \\
(\mathrm{MHz}, \%)\end{array}$ & $\begin{array}{c}\text { Peak Gain } \\
(\mathrm{dBi})\end{array}$ \\
\hline 1(a) & 674,44 & $682,44.2$ & 7.1 \\
\hline 1(c) & $729,47.2$ & $738,47.6$ & 7.1 \\
\hline $\begin{array}{c}\text { 1(c), different } \\
\mathrm{S}_{1}\end{array}$ & $823,50.8$ & $836,51.1$ & 7.4 \\
\hline 5 (a) & $780,52.5$ & $794,53.2$ & 8.0 \\
\hline $\begin{array}{c}\text { 5 (a), } \\
\text { different } \mathrm{S}_{1}\end{array}$ & $845,53.6$ & 862,54 & 7.8 \\
\hline $7(\mathrm{a})$ & $785,51.6$ & $804,52.5$ & 7.8 \\
\hline 9(a) & $788,51.8$ & $802,52.3$ & 7.7 \\
\hline $10(\mathrm{~b})$ & $810,52.4$ & $824,53.2$ & 7.8 \\
\hline
\end{tabular}
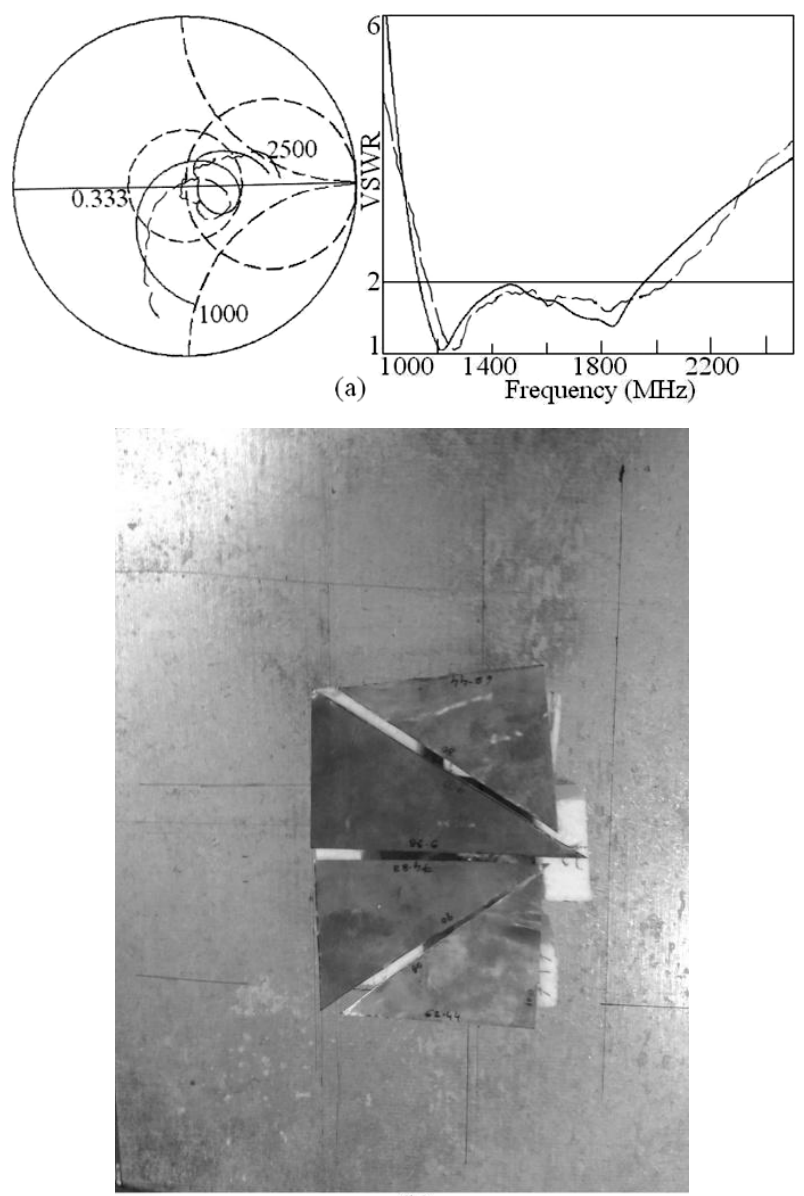

(b)

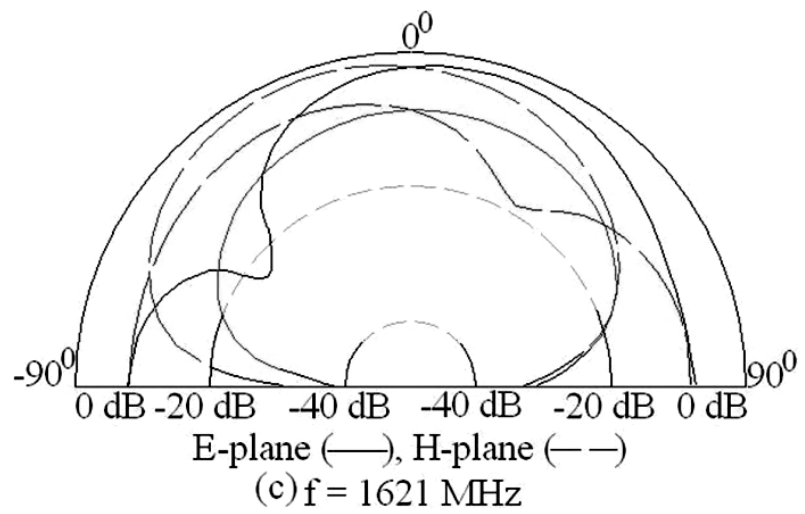

Fig. 11 (a) Input impedance and VSWR plots, $(-)$ simulated, (--) measured, (b) fabricated prototype and (c) radiation pattern at center frequency for proximity fed unequal dimension HETMSAs gap-coupled to equal dimension HETMSAs

\section{CONCLUSIONS}

Various broadband gap-coupled proximity fed configurations of ETMSA and its compact variation HETMSA, are proposed. The gap-coupled parasitic HETMSAs are coupled along the side edges of ETMSA, thereby not increasing overall patch size. The proximity fed ETMSA yields BW of more than 650 $\mathrm{MHz}(>40 \%)$ whereas proximity fed gap-coupled equal and unequal dimension ETMSAs yields BW of nearly 800 and $850 \mathrm{MHz}(>50 \%)$, respectively. The increase in gain and BW of proximity fed ETMSA and HETMSAs is realized by gapcoupling them with parasitic HETMSAs of equal and unequal 
dimensions. These gap-coupled configurations yields BW in the range of $800 \mathrm{MHz}(>50 \%)$ with broadside radiation pattern and peak gain of nearly $8 \mathrm{dBi}$. Out of all these gapcoupled MSAs, proximity fed ETMSA gap-coupled with equal and unequal dimension HETMSAs yields optimum results in terms of BW, gain and radiation pattern.

\section{REFERENCES}

[1] Kumar, G., and Ray, K. P. 2003, Broadband Microstrip Antennas, First Edition, USA, Artech House

[2] Bhartia, B., and Bahl, I. J. 1980, Microstrip Antennas, USA

[3] Garg, R., Bhartia, P., Bahl, I., and Ittipiboon, A., Microstrip Antenna Design Handbook, 2001, Artech House, USA.

[4] Cock, R. T. and Christodoulou, C. G. 1987. Design of a two layer capacitively coupled, microstrip patch antenna element for broadband applications, IEEE Antennas Propag. Soc. Int. Symp. Dig., vol. 2, (1987), 936-939.

[5] Wong, K. L. 2002. Compact and Broadband Microstrip Antennas, John Wiley \& sons, Inc., New York, USA

[6] Deshmukh, Amit A., and Kumar, G. 2005. Compact Broadband gap-coupled Shorted L-shaped Microstrip Antennas, Microwave and Optical Technology Letters, vol. 47 , no. 6 , (20 ${ }^{\text {th }}$ Dec. 2005$), 599-605$.

[7] Deshmukh, Amit A., and Kumar, G. 2006. Compact Broadband stacked Microstrip Antennas, Microwave and Optical Technology Letters, vol. 48, no. 1, (Jan. 2006), $93-96$.

[8] Deshmukh, Amit A., and Kumar, G. 2006. Compact Broadband Rectangular Microstrip Antennas, Microwave and Optical Technology Letters, vol. 48, no. 6, (June 2006), $1043-1046$
[9] Deshmukh, Amit A., and Kumar, G. 2006. Compact Broadband Gap-coupled Shorted Square Microstrip Antennas, Microwave and Optical Technology Letters, vol. 48, no. 7, (July 2006), 1261 - 1265.

[10] Huynh, T., and Lee, K. F. 1995. Single-Layer SinglePatch Wideband Microstrip Antenna, Electronics Letters, vol. 31, no. 16, (August 1995), 1310-1312.

[11] Guo, Y. X., Luk, K. M., Lee, K. F., and Chow, Y. L. 1998. Double U-slot Rectangular Patch Antenna, Electronics Letters, vol. 34, (1998), 1805 - 1806

[12] Sharma, S. K., and Shafai, L. 2009. Performance of a Novel $\Psi$-Shaped Microstrip Patch Antenna with Wide Bandwidth, IEEE Antennas \& Wireless Propagation Letters, vol. 8, (2009), $468-471$.

[13] Lee, K. F., Yang, S. L. S., Kishk, A. A., and Luk, K. M. 2010. The Versatile U-slot Patch, IEEE Antennas \& Propagation Magazine, vol. 52, no. 1, (February 2010), $71-88$.

[14] Wong, K. L., and Hsu, W. H. 2001. A Broadband Rectangular Patch Antenna with a Pair of wide slits, IEEE Transactions on Antennas \& Propagation, Vol. 49, No. 9, (September 2001), 1345 - 1347.

[15] Yang, F., Zhang, X., Yc, X., and Sammi, Y. R. 2001 Wide-band E-shaped patch antennas for wireless communication, IEEE Transactions on Antennas \& Propagation, vol. 49, no. 7, (July 2001), $1094-1100$.

[16] Lee, K. F., Yang, S. L. S., and Kishk, A. A. 2008. Dual and Multi-band U-slot patch Antennas, IEEE Antennas and wireless Propagation Letters, vol. 7, (2008), 645 647.

[17] IE3D 12.1, 2004. Zeland Software, Freemont, USA 